\title{
LoSS of SET1/COMPASS methyltransferase activity reduces lifespan and fertility in Caenorhabditis elegans
}

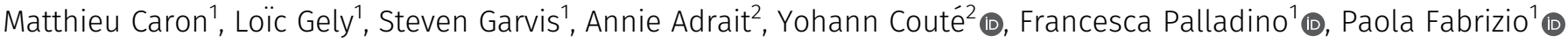

\begin{abstract}
Changes in histone post-translational modifications are associated with aging through poorly defined mechanisms. Histone 3 lysine 4 (H3K4) methylation at promoters is deposited by SET1 family methyltransferases acting within conserved multiprotein complexes known as COMPASS. Previous work yielded conflicting results about the requirement for $\mathrm{H} 3 \mathrm{~K} 4$ methylation during aging. Here, we reassessed the role of SET1/COMPASS-dependent H3K4 methylation in Caenorhabditis elegans lifespan and fertility by generating set-2(syb2085) mutant animals that express a catalytically inactive form of SET-2, the C. elegans SET1 homolog. We show that set-2(syb2085) animals retain the ability to form COMPASS, but have a marked global loss of H3K4 di- and trimethylation (H3K4me2/3). Reduced H3K4 methylation was accompanied by loss of fertility, as expected; however, in contrast to earlier studies, set-2(syb2085) mutants displayed a significantly shortened, not extended, lifespan and had normal intestinal fat stores. Other commonly used set-2 mutants were also short-lived, as was a cfp-1 mutant that lacks the SET1/COMPASS chromatintargeting component. These results challenge previously held views and establish that WT H3K4me2/3 levels are essential for normal lifespan in C. elegans.
\end{abstract}

DOI 10.26508/Isa.202101140 | Received 22 June 2021 | Revised 25 November 2021 | Accepted 26 November 2021 | Published online 10 December 2021

\section{Introduction}

Epigenetic alterations, such as post-translational histone modification and DNA methylation, are well-established hallmarks of cellular senescence and organismal aging $(1,2)$. Two important consequences of these modifications are transcriptional deregulation and increased genome instability, which are thought to play key roles in aging and age-related diseases (1). However, the complexity of the aging epigenome, especially in mammals, has hampered efforts to establish whether and how individual epigenetic alterations contribute to the aging process. Studies in simple model organisms have provided valuable insight into this question. Work in yeast, worms, and flies has shown that nutrient-regulated signaling pathways, such as the insulin/IGF-1 and target of rapamycin pathways, play conserved roles in the regulation of mammalian lifespan $(3,4)$. More recent studies in these model systems have sought to establish a causal link between specific epigenetic modifications and the aging process. For example, overexpression of $\mathrm{H} 3$ and $\mathrm{H} 4$ histones in WT budding yeast is sufficient to extend lifespan, suggesting that the observed loss of histones during replicative aging directly contributes to the aging process $(5,6)$. Global loss of histones is also observed in aging Caenorhabditis elegans, senescent human cells, and human fibroblasts undergoing replicative aging $(7,8,9)$, suggesting that a decline in core histone proteins may represent a conserved aging mechanism.

Loss of heterochromatin is another feature widely regarded as a contributor to the aging process (10). In aging organisms, senescent cells, and models of progeroid syndromes, loss of heterochromatin is associated with a decrease in the abundance of the repressive trimethylated histone 3 lysine 9 (H3K9me3) mark and of heterochromatin protein 1 (HP1) $(10,11)$. The abundance of another repressive mark, H3K27me3, also declines with time, but the manner in which aging affects this mark differs substantially not only between organisms but also between tissues within the same organism $(2,11)$. In C. elegans, loss of H3K27me3 in aging somatic cells is accompanied by transcriptional up-regulation of UTX-1, a demethylase responsible for H3K27me3 removal (12). Notably, reducing UTX-1 levels by RNAi reverses the age-dependent decline in H3K27me3 and prolongs lifespan $(12,13)$, suggesting that maintenance of this mark is associated with a delay in chronological aging. In contrast, Drosophila carrying mutations that affect polycomb repressor complex 2 components have reduced global levels of H3K27me3, but the males exhibit an extended lifespan (14). Although the reason for these opposing effects of H3K27me3 removal on the lifespans of worms and flies is unclear, it most likely involves altered expression of a few key target genes rather than global changes in H3K27me3 distribution (13). Similarly, misregulation of distinct sets of target genes may also account for the extended lifespan of $C$. elegans induced by either inactivation or overexpression of UTX-1 (15).

Histone modifications associated with active chromatin, such as H3K4me3 and H3K36me3, are also subject to age-dependent

${ }^{1}$ Laboratory of Biology and Modelling of the Cell, Ecole Normale Supérieure de Lyon, CNRS UMR5239, INSERM U1210, Université de Lyon, Lyon, France ${ }^{2}$ University of Grenoble Alpes, INSERM, CEA, UMR BioSanté U1292, CNRS, CEA, FR2048, Grenoble, France

Correspondence: francesca.palladino@ens-lyon.fr; paola.fabrizio@ens-lyon.fr 
deregulation and have been implicated in lifespan regulation (16). H3K4me3, a mark associated with active promoters, has context-dependent functions in gene regulation (17). In yeast, H3K4 methylation is deposited exclusively by the methyltransferase Set1, which acts as part of the multisubunit complex of proteins associated with Set1 (COMPASS) $(18,19)$. Mammals express at least six proteins capable of methylating H3K4: two Set1-related proteins, Set1A and Set1B, and four more distantly related MLL proteins (MLL$1-4)$, which are found in distinct SET or MLL COMPASS complexes that share the core regulatory components Swd3/WDR5, Swd1/ RbBP5, Bre2/ASH2, and Sdc1/hDPY30 (17, 20, 21, 22, 23, 24, 25, 26). In the mouse, all six Set1 and MLL proteins have been shown to be essential for survival (17). Whereas SET1/COMPASS complexes control global H3K4 methylation, MLL/COMPASS-like complexes methylate $\mathrm{H} 3 \mathrm{~K} 4$ at specific gene targets or regulatory regions (17). In C. elegans, the single homologs of SET1 and MLL, SET-2 and SET-16, respectively $(27,28)$, also display different functions. SET-2 deposits most H3K4me3 marks in both the germline and soma (27, 28), and worms lacking SET-2 are viable but have reduced fertility; in contrast, loss of SET-16 causes embryonic lethality, consistent with studies of mammalian MLL proteins $(29,30)$.

The role of H3K4me3 in lifespan regulation is controversial and conflicting results have been obtained with several model organisms. Yeast set1 mutants are short-lived in both replicative and chronological aging paradigms $(31,32,33)$. Set1-dependent H3K4me3 promotes chronological longevity in yeast by preventing apoptosis and histone loss, and the mark also contributes to the maintenance of transcriptional patterns required for a normal replicative lifespan $(31,32,33)$. Conversely, partial loss-of-function mutations or knockdown of genes encoding the SET1/COMPASS components SET-2, WDR-5.1, and ASH-2 in C. elegans have been shown to extend lifespan through changes in lipid metabolism triggered by the germline $(34,35)$. The lifespan-extending effect observed in wdr-5.1 and set-2 mutants was transmitted transgenerationally, and WT descendants of wdr-5.1 or set-2 mutants over several generations were also long-lived (36). More recently, this transgenerational effect was attributed to a generationdependent accumulation of repressive H3K9me2 (37). However, these studies did not investigate whether loss of $\mathrm{H} 3 \mathrm{~K} 4$ methylation or acquisition of H3K9 methylation may have contributed to the effects by directly altering the expression of germline genes that affect longevity.

To address the role of $\mathrm{H} 3 \mathrm{~K} 4$ methylation in C. elegans lifespan, we generated a mutant that is unable to mediate $\mathrm{H} 3 \mathrm{~K} 4$ methylation but retains the ability to form a SET1/COMPASS complex, thereby avoiding interference with potential non-catalytic complex activities. To this end, we generated mutants carrying a catalytically inactive allele of set-2 using CRISPR/Cas9 editing and analyzed the effects on SET1/COMPASS complex assembly, H3K4 di- and trimethylation, fat accumulation, fertility, and, most importantly, lifespan. Interestingly, mutants with catalytically inactive SET-2 displayed some, but not all, of the previously characterized phenotypes of $C$. elegans mutants harboring varying degrees of SET-2 loss of function, with the most striking difference being the shortened, rather than extended, lifespan of our mutants compared with WT animals (34). Overall, the results of this study suggest a more complex, and likely context-dependent, requirement for SET1/COMPASS-mediated H3K4 methylation in the maintenance of normal lifespan in C. elegans.

\section{Results}

\section{A catalytically inactive set-2 allele reduces global $\mathrm{H} 3 \mathrm{~K} 4 \mathrm{di}-$ and trimethylation in C. elegans}

Earlier studies suggesting that loss of $\mathrm{H} 3 \mathrm{~K} 4$ trimethylation extends C. elegans lifespan were performed using set-2 RNAi knockdown or a set-2 partial loss-of-function allele, set-2(ok952) $(34,35,36)$. The set-2(ok952) mutation is a complex insertion/deletion that encodes a SET-2 protein with an intact catalytic SET domain but missing an upstream region (Fig 1A); accordingly, set-2(ok952) animals show only a small reduction in global H3K4me3 levels in the soma and germline and no obvious phenotype (27). To more directly investigate how SET1/COMPASS-dependent methylation contributes to lifespan in C. elegans, we engineered a catalytically inactive set-2 allele, set-2(syb2085), by replacing the highly conserved histidine $(\mathrm{H})$ residue at amino acid position 1447 of the SET domain with lysine (K) using CRISPR-Cas9 technology (Fig 1A). This residue is conserved in the great majority of SET domain proteins regardless of the histone substrate specificity, and structural studies as well as in vitro and in vivo assays have demonstrated its requirement for histone methyltransferase activity (38, 39, 40, 41, 42, 43, 44, 45, 46, 47). Immunofluorescence staining of set-2(syb2085) animals revealed a marked decrease in $\mathrm{H} 3 \mathrm{~K} 4 \mathrm{me} 3(\sim 80 \%)$ in the germline compared with WT (N2) animals (Fig 1B and C). Moreover, the H3K4me3 reduction in set-2(syb2085) animals was comparable to that observed in set-2(bn129) null mutants previously described (29) and in cfp1(tm6369) mutants lacking the SET1/COMPASS component CFP-1 (48) (Fig 1B and C). Consistent with the earlier work, H3K4me3 levels in the germline of set-2(ok952) animals were relatively modestly reduced compared with WT worms (27) (Fig 1B and C). Similar results were obtained when the germlines were immunostained for H3K4me2, which is also mediated by SET1/COMPASS in C. elegans (Fig 1B and C) (29). The immunostaining results were confirmed by Western blot analysis of mixed staged embryos followed by semiquantitation of H3K4me2 and H3K4me3 (Fig 2A and B). No significant differences in $\mathrm{H} 3 \mathrm{~K} 4 \mathrm{me} 2 / 3$ levels were detected between WT and set-2(ok952) embryos, whereas both histone marks were reduced by $\sim 60 \%$ in set-2(bn129), set-2(syb2085), and cfp-1(tm6369) mutants. Taken together, our results demonstrate that the levels of H3K4me2/ 3 in set-2(syb2085) animals are reduced to levels comparable to those seen in set-2 null animals, consistent with complete loss of set- 2 catalytic activity. The residual $\mathrm{H} 3 \mathrm{~K} 4 \mathrm{me} 2 / 3$ observed in both germlines and embryos is most likely due to SET-16, the only other known SET1 family protein in C. elegans $(29,49)$.

To verify that loss of SET-2 catalytic activity in set-2(syb2085) mutants does not interfere with SET-2 protein stability or SET1/ COMPASS integrity, we performed co-immunoprecipitation and mass spectrometry-based proteomic analyses using a newly generated C. elegans strain expressing a gfp::cfp-1 knock-in allele [cfp-1(syb1012)]. These experiments showed that immunoprecipitates of GFP::CFP-1 from lysates of set-2(syb2085) mutant embryos 
A

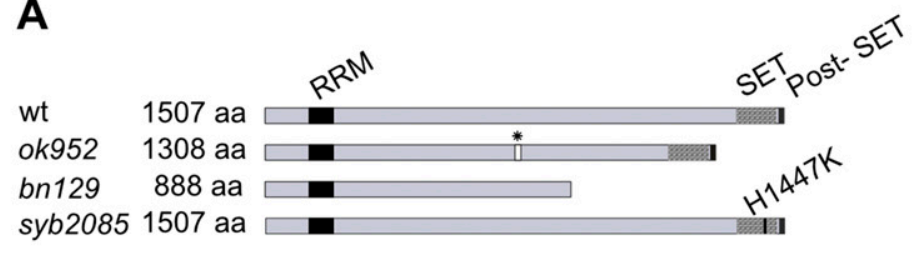

SET domain

SET-2 C.elegans SET1 S.cerevisiae MLL1 H.sapiens SET7/9 H.sapiens

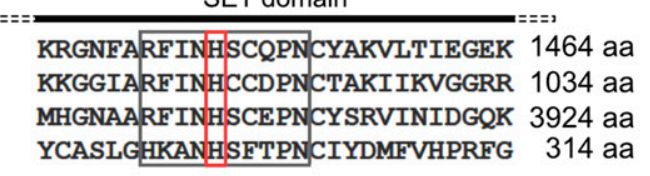

B

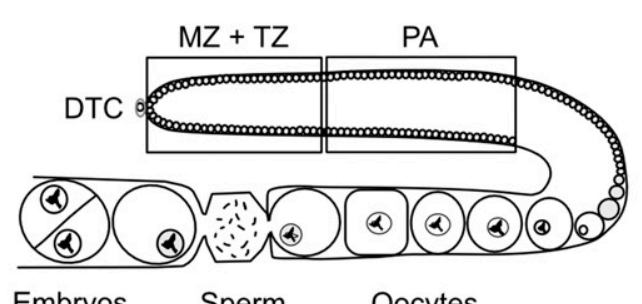

Embryos Sperm Oocytes

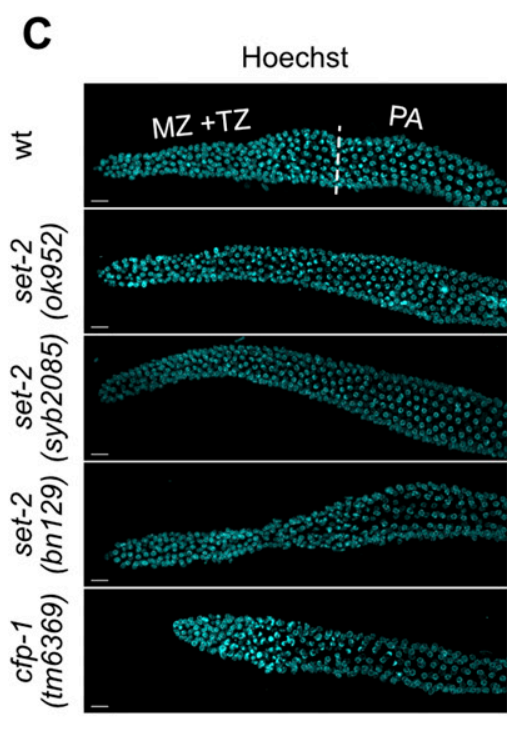

$\mathrm{MZ}+\mathrm{TZ} \mathrm{H} 3 \mathrm{~K} 4 \mathrm{me} 3$

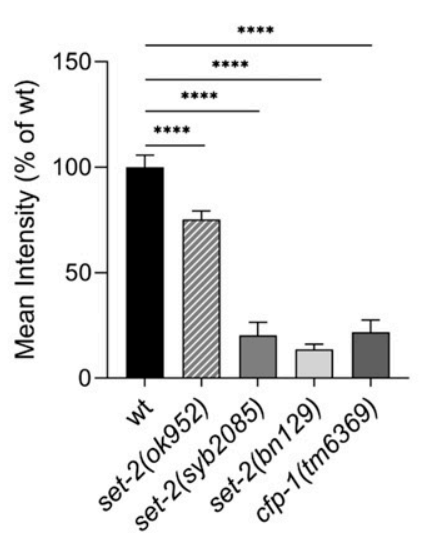

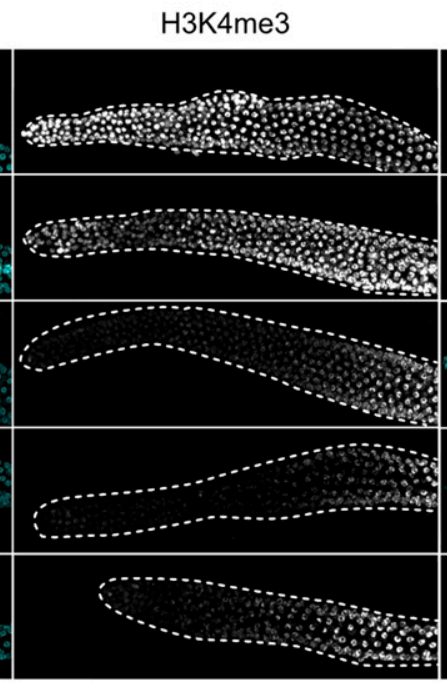

PA H3K4me3

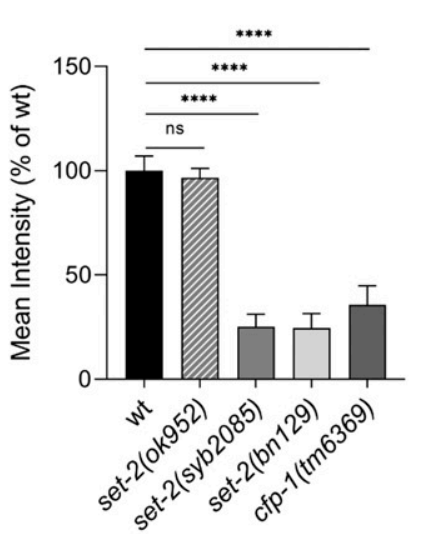

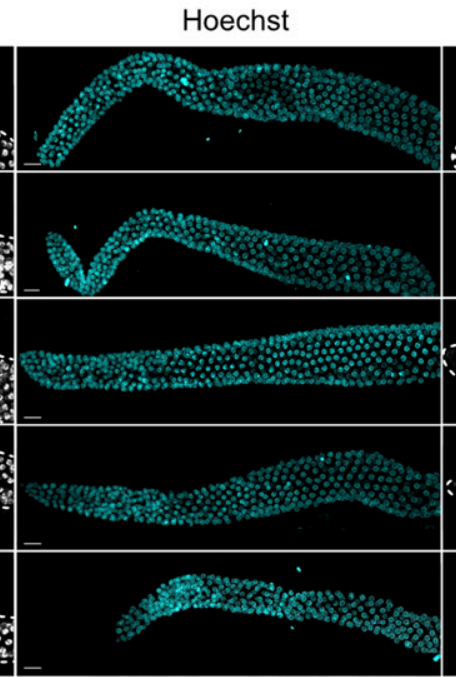

$\mathrm{MZ}+\mathrm{TZ} \mathrm{H} 3 \mathrm{~K} 4 \mathrm{me} 2$

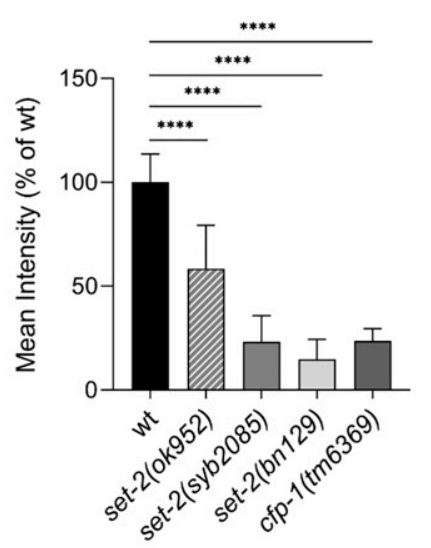

H3K4me2

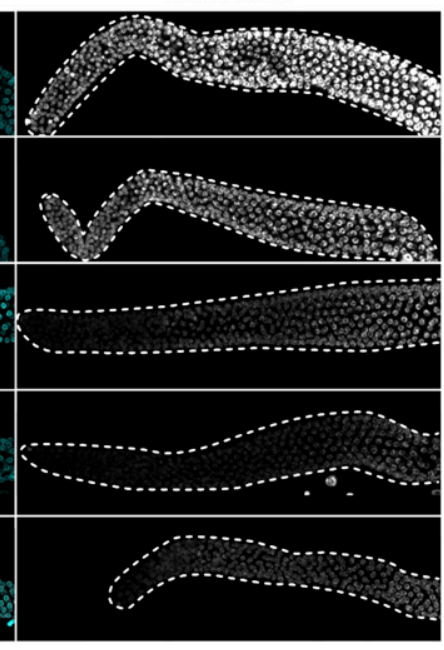

PA H3K4me2

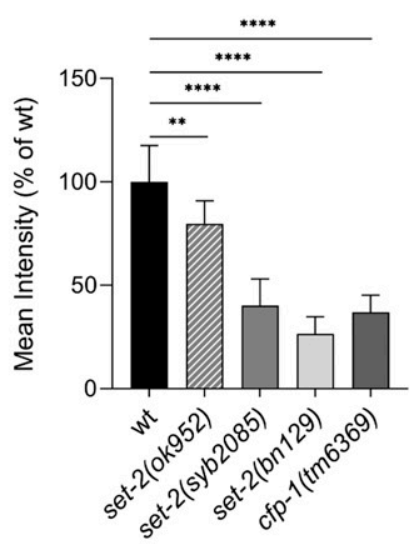

Figure 1. Loss of SET-2 enzymatic activity in Caenorhabditis elegans markedly reduces H3K4me3 and H3K4me2 in the germline.

(A) Upper panel: schematic showing the set-2 alleles used in this study. Black and shaded boxes represent conserved domains (RRM, SET, and post-SET). The position of the amino acid substitution introduced within the SET domain of set-2(syb2085) is shown. Asterisk indicates a 12 bp-insertion present in the set-2(ok952) allele. Lower panel: sequence alignment of the conserved SET domain motif (black box) from selected H3K4 histone methyltransferases including the His residue mutated in set2(syb2085) (red box). (B) Schematic showing the regions of the germline used for quantification of immunofluorescence signals: mitotic zone (MZ), transition zone (TZ), and pachytene (PA). DTC, distal tip cell. (C) Representative confocal images of dissected gonads from WT animals and the indicated set-2 or cfp-1 mutants stained with Hoechst and anti-H3K4me3 antibody (left panels) or anti-H3K4me2 (right panels). Scale bar, $10 \mu \mathrm{m}$. Lower bar graphs show quantification of $\mathrm{H} 3 \mathrm{~K} 4 \mathrm{me} / 2$ signals normalized to Hoechst in the MZ + TZ and PA regions. Data show changes in the mean pixel intensities expressed as percent of the WT $\pm S D, n=10$. ns, not significant, **P $<0.005$, **** $P<0.0001$ for mutants versus WT worms by one-way ANOVA followed by Tukey's test. 
A

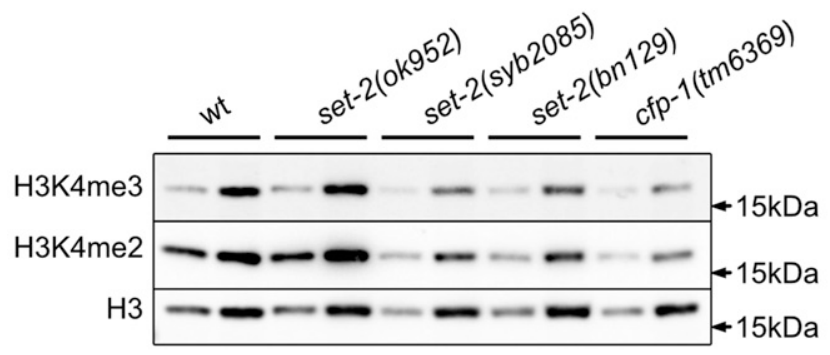

B

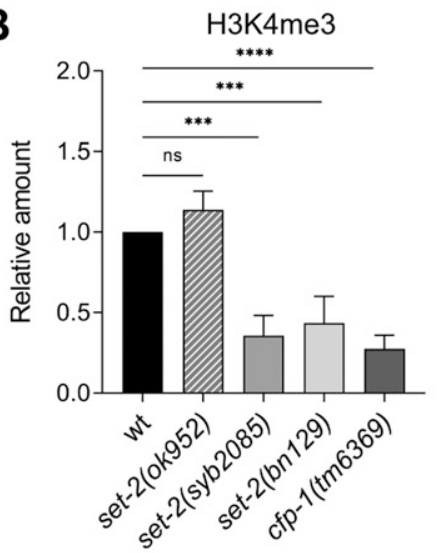

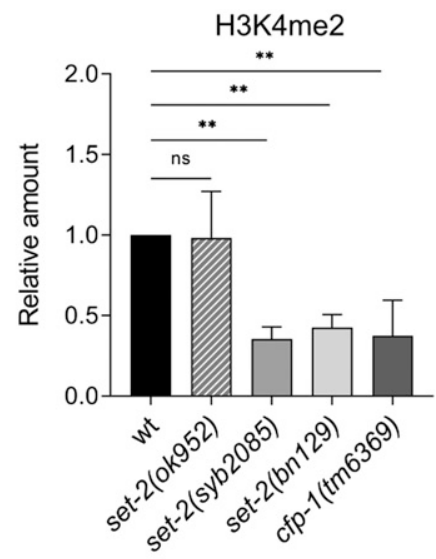

C

\begin{tabular}{|c|c|c|c|c|c|}
\hline \multicolumn{2}{|c|}{ protein name } & \multicolumn{4}{|c|}{ GFP::CFP-1 Co-IP, SC (number/sample) } \\
\hline C. elegans & Mammals & set-2(+) & set-2(ok952) & set-2(syb2085) & control \\
\hline CFP-1 & CFP1 & 100 & 135 & 163 & 0 \\
\hline SET-2 & SET1 & 64 & 66 & 106 & 0 \\
\hline SWD-2.1 & WDR82 & 19 & 13 & 17 & 0 \\
\hline RBBP-5 & RbBP5 & 58 & 72 & 78 & 0 \\
\hline ASH-2 & ASH2 & 81 & 92 & 102 & 0 \\
\hline WDR-5.1 & WDR5 & 26 & 27 & 34 & 1 \\
\hline DPY-30 & DPY30 & 1 & 1 & 1 & 0 \\
\hline
\end{tabular}

Figure 2. Loss of SET-2 catalytic activity causes a global reduction in H3K4me3 and H3K4me2 in Caenorhabditis elegans embryo.

(A) Western blot analysis of proteins from mixed stage embryos of WT and the indicated set-2 or cfp-1 mutants. Blots were probed with anti-H3K4me3, anti-H3K4me2, and anti-H3 antibodies. Left and right lanes for each strain represent samples with 1 and $3 \mu \mathrm{g}$ total protein, respectively. (A, B) Quantification of H3K4me3 (left) and H3K4me2 (right) band intensities from blots represented in (A). Mean $\pm S D, n=3$. ns, not significant, ${ }^{* \star} P<0.01,{ }^{* \star *} P<0.001$, ${ }^{* \star * \star} P<0.0001$ for mutants versus WT worms by one-way ANOVA followed by Dunnett's test. (C) List of selected proteins (and their mammalian homologs) identified by mass spectrometry of proteins immunoprecipitated with GFP::CFP-1 from embryos carrying the indicated set-2 alleles. SET-2/SET1 complex specific components and SET1/MLL core complex components are highlighted in light and dark gray, respectively. SC, spectral counts. Control samples were obtained from WT animals not carrying the GFP::CFP-1 allele.

contained SET-2, the core SET1/COMPASS components ASH-2, RBBP-5, WDR-5.1, and DPY-30, and the unique subunit SWD-2.1 (Fig $2 \mathrm{C}$ and Table S1). Similar results were obtained in CFP-1 immunoprecipitates from set-2(ok952) mutant embryos (Fig 2C and Table S1), whereas none of the SET1/COMPASS subunits were detected in immunoprecipitates from set-2(bn129) null mutants (Table S2). Taken together, these results indicate that SET1/COMPASS formation is maintained in set-2(syb2085) mutant animals, and indicate that disruption of the complex is not responsible for the loss of $\mathrm{H} 3 \mathrm{~K} 4$ methylation in these mutants.

\section{Partial or complete set-2 inactivation or loss of SET-2 catalytic activity shortens lifespan}

As noted above, previous work suggested that loss of H3K4 trimethylation in set-2(ok952) mutants results in lifespan extension, potentially via modulation of fat metabolism (35). To determine whether loss of $\mathrm{H} 3 \mathrm{~K} 4 \mathrm{me} 2 / 3$ in the catalytically inactive SET-2 mutants was associated with similar effects on lifespan, we compared set-2(syb2085) animals with N2 WT worms and set-2(ok952), set-2(bn129), and cfp-1(tm6369) mutants, all of which display varying H3K4me2/3 levels. Unexpectedly, we observed a significant and reproducible reduction in the mean lifespan not only of set-2(syb2085), set-2(bn129), and cfp-1(tm6369) mutants but also of set-2(ok952) mutants, which had previously been described as exhibiting increased longevity compared with WT animals (Fig 3A and Table S3). Our finding that each of the SET1/ COMPASS mutants displayed decreased lifespans compared with WT animals are consistent with recent work showing similar effects on longevity in set-2(bn129) mutants, ash-2 mutants (50), and early generations of $w d r-5$ mutants (37).

Because the previous study examining set-2(ok952) animals attributed the extended lifespan to altered lipid metabolism (35), we used Oil Red O staining to quantify levels of neutral lipids, the main form of lipid storage in C. elegans. However, we observed no significant differences in neutral lipid content between WT animals and either set-2(ok952) or set-2(syb2085) animals. As previously shown, lipid stores were increased in insulin signaling daf-2(e1370) mutants that show extended lifespan, and decreased in eat2(ad1116) mutants defective in pharyngeal pumping (Fig 3B and $C$ and Table S3) $(51,52,53)$. Consistent with our results, in an independent study lipid content was found to be unaltered in $w d r-5$ loss-of-function mutants (54). These results demonstrate that loss of catalytic activity in SET1/COMPASS and a corresponding reduction in global H3K4me2/3 not only shortens lifespan in $C$. elegans but also does so without modifying neutral lipid content. 
A

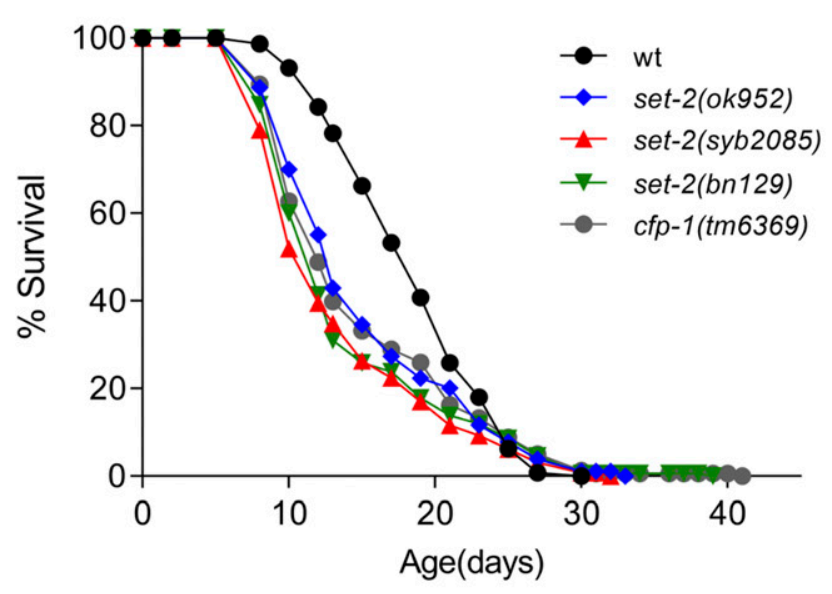

B

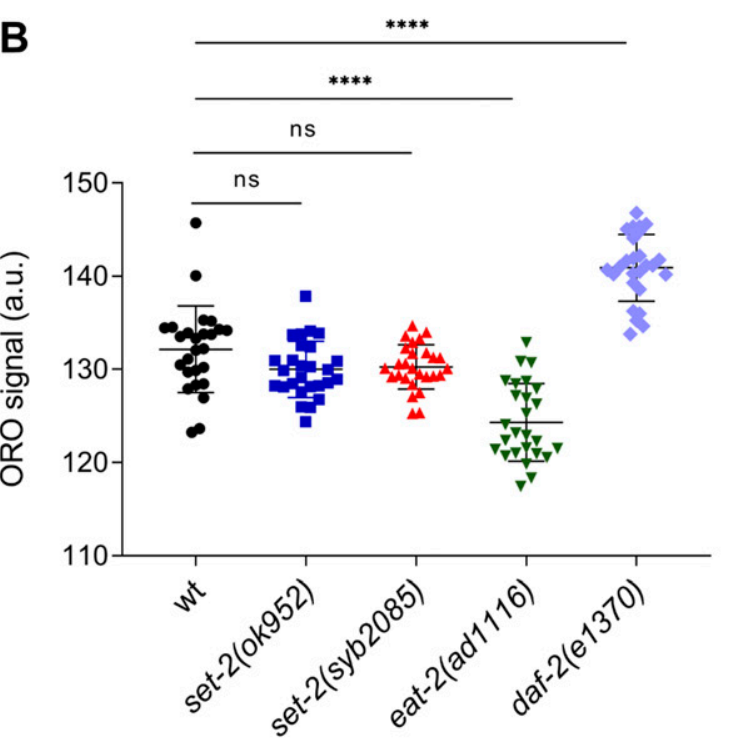

C

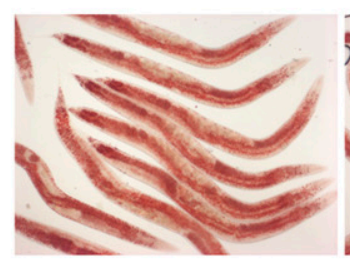

wt

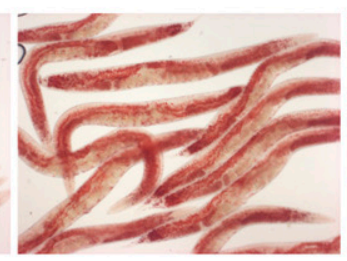

set-2 (ok952)

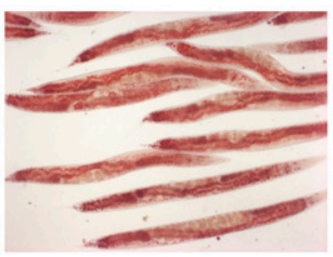

set-2 (syb2085)

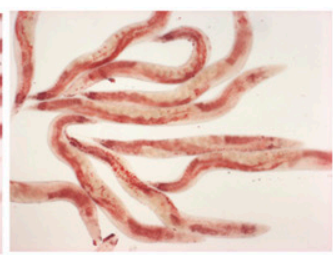

eat-2 (ad1116)

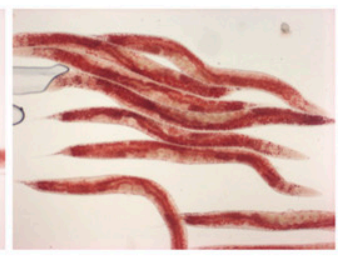

daf-2 (e1370)

Figure 3. Loss of SET-2-dependent methylation reduces lifespan.

(A) Lifespan assays of WT Caenorhabditis elegans and set-2 and cfp-1 mutants. Mean reductions relative to WT animals are $17.6 \%$ for set-2(ok952) ( $P<0.001), 26 \%$ for set2(syb2085) $(P<0.0001), 23.3 \%$ for set-2(bn129) $(P<0.0001)$, and 18.3\% for cfp-1(tm6369) $(P<0.001)$. $P$-values were calculated using the Mantel-Cox log-rank method. Replicate experiments are shown in Table S3. (B, C) Quantification of Oil Red O signal intensity and (C) representative images of Oil Red O-stained WT, set-2(ok952), set2(syb2085), eat-2(ad1116), and daf-2(e1370) animals. Magnification = 10*. Data represent the mean intensity \pm SD of $n=27$ worms. ns, not significant; **** $P<0.0001$ by oneway ANOVA followed by Tukey's test.

\section{Loss of SET-2-dependent H3K4 methylation is responsible for loss of fertility}

We considered that the reduced lifespan exhibited by set-2 mutants could result from developmental defects (55). However, we found that the development time of set-2(syb2085) and set-2(ok952) animals was only modestly lengthened compared with that of WT animals ( $\sim 67, \sim 64$, and $\sim 62 \mathrm{~h}$, respectively; Fig S1). This finding suggests that the shortened lifespan of set-2(syb2085) animals is unlikely to be due to major developmental defects, although we cannot exclude a contribution from more subtle defects in neuronal development (56).

Inactivation of SET1/COMPASS components has been shown to disrupt (29) or have no effect (34) on C. elegans fertility. Therefore, we analyzed fertility phenotypes in set-2(syb2085), set-2(bn129), and set2(ok952) animals. We found that loss of SET-2 catalytic activity resulted in fertility defects similar to those of set-2 null animals, including decreased brood size under normal growth conditions $\left(20^{\circ} \mathrm{C}\right)$ and progressive sterility at a higher temperature $\left(25^{\circ} \mathrm{C}\right)$, although the defects were less severe than in set-2(bn129) mutants (Fig $4 A$ and B) (57). As previously reported, the fertility phenotypes of set2(ok952) animals were not significantly different from those of WT animals (Fig 4A and B) (57). Collectively, these results indicate that
SET1/COMPASS-dependent H3K4 di- and trimethylation play a crucial role in maintaining germline homeostasis.

\section{Discussion}

Previous studies using partial knockdown of SET1/COMPASS subunits have led to the commonly held view that loss of H3K4 trimethylation increases lifespan in C. elegans $(1,2)$. More recent studies suggested that this effect is observed only after multiple generations of knockdown of SET1/COMPASS components and depends on the accumulation of repressive H3K9me2 (37). In the present work, we sought to clarify whether SET1/COMPASSdependent H3K4 methylation affects longevity by examining $C$. elegans mutants in which the catalytic activity of SET-2 was selectively inactivated, thereby leaving other functions of the protein and/or COMPASS unaltered. We found not only that SET-2-mediated H3K4 methylation is essential for a normal lifespan, but also that, in contrast to earlier studies, even a mild reduction in SET-2 activity is detrimental to lifespan, as demonstrated by set2(ok952) animals. 
A

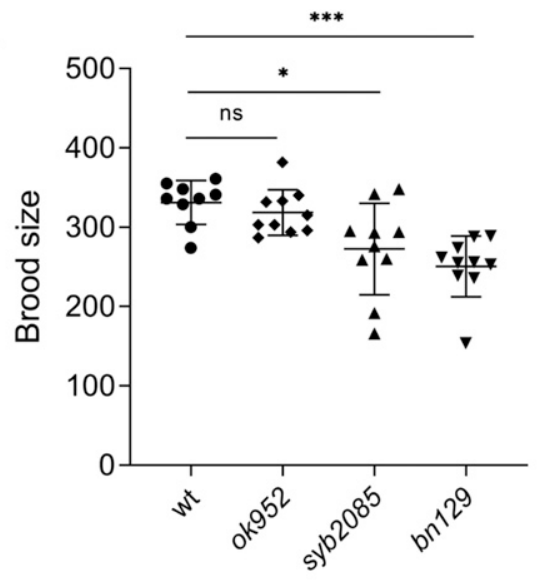

B

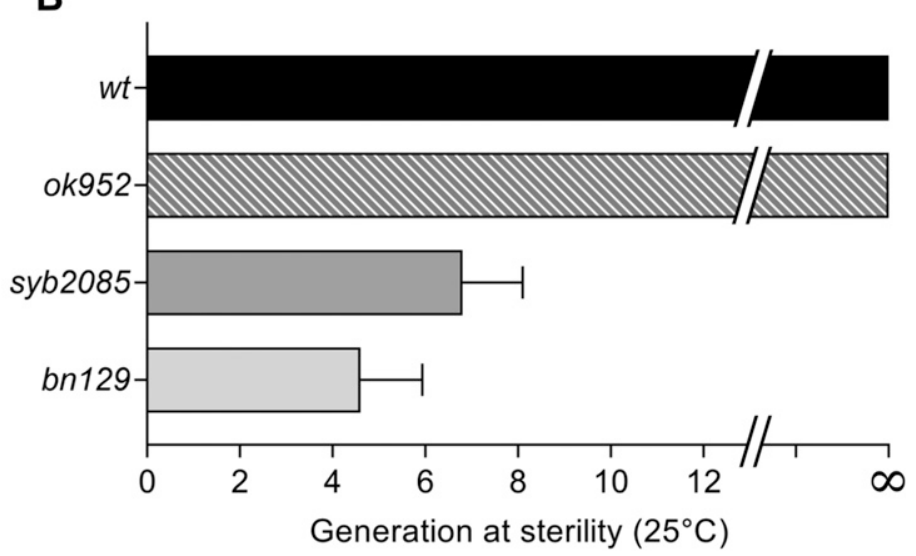

Figure 4. SET-2 catalytic activity is required for germline immortality.

(A) Total number of progeny from WT, set-2(ok952), set-2(syb2085), and set-2(bn129) animals grown at $20^{\circ} \mathrm{C}$. Data represent the mean $\pm S D, n=10$. ns, not significant; ${ }^{*} P<0.05,{ }^{* \star \star} P<0.001$ for set-2(syb2085) and set-2(bn129) versus WT, respectively, by one-way ANOVA followed by Tukey's test. (B) Transgenerational fertility assay of WT animals and the indicated set-2 mutants performed at $25^{\circ} \mathrm{C}$. Scoring was based on five biological replicates, with six independent lines each, error bars show SD. WT animals can be maintained for more than 40 generations without loss of fertility (48).

We observed decreased longevity in set-2(bn129) mutants, which as shown here fail to form a SET1/COMPASS complex, as well as in set-2(syb2085) animals. Both mutants also exhibited similar global loss of H3K4me2/3 methylation in the germline and soma, decreased fertility at $20^{\circ} \mathrm{C}$, and progressive sterility at the stressful temperature of $25^{\circ} \mathrm{C}$. Recent reports for several histone-modifying complexes suggest that they play important functions independent of catalytic activity (58). Our results strongly suggest that the shortened lifespan and loss of fertility phenotypes of set-2 mutants result from loss of $\mathrm{H} 3 \mathrm{~K} 4 \mathrm{di}$ - and trimethylation rather than catalytic-independent functions of SET-2. Of note, we found that cfp-1 mutants lacking the CFP-1 chromatin-targeting subunit of COMPASS also exhibited reduced lifespan. Thus, although we cannot exclude that loss of methylation of a non-histone substrate contributes to the observed phenotypes of set-2(syb2085) animals, our results are most consistent with a crucial role for SET1/COMPASSdependent H3K4 methylation in maintaining a normal lifespan, in addition to its previously documented role in promoting germ cell survival $(29,49,57)$.

An earlier study reported that the lifespan of set-2(ok952) mutant animals was $20 \%$ longer than that of WT animals (34), which contrasts with observations in the present study. We were also unable to recapitulate the increase in lipid storage previously implicated in the lifespan extension of set-2(ok952) animals (35). Indeed, neither set-2(ok952) nor set-2(syb2085) mutants showed a detectable change in intestinal lipid content compared with WT worms in our study. We found that the mutant SET-2 protein in set-2(ok952) animals retains its ability to associate with other SET1/COMPASS components and exhibits only a small decrease in H3K4 methylation compared with WT animals, consistent with the presence of an intact SET-2 catalytic domain $(27,49)$. The causes for the discrepancies in lifespan of set-2(ok952) animals in the present and earlier study could be partly related to subtle experimental differences such as reagent purity and quality, or small variations in incubator temperature and/or humidity $(59,60)$. The genetic background of $\mathrm{C}$. elegans mutants has been shown to influence lifespan (61), and additional mutations could have contributed to the observed differences in the lifespan of set-2(ok952) mutants (34). More recent studies suggest that changes in lifespan may not be observed for $\geq 20$ generations in animals with reduced $\mathrm{H} 3 \mathrm{~K} 4$ methylation, as shown for C. elegans mutants lacking WDR-5.1 (37). In the present study we did not test whether the detrimental effect on lifespan caused by losS of SET1/COMPASS activity is reversed after multiple generations. We note, however, that not only is WDR-5.1 a common component of both SET1/ and MLL/COMPASS complexes, but is also present in other multiprotein complexes with histone-modifying activity in C. elegans and other species $(48,62,63,64,65)$. In addition, WDR-5.1 also has established COMPASS/H3K4 methylation-independent functions (66). Therefore, the context in which WDR-5.1 influences lifespan remains to be established and a SET1/COMPASS-independent mechanism is plausible.

Our results show a direct correlation between loss of $\mathrm{H} 3 \mathrm{~K} 4 \mathrm{me} 2 / 3$ in the germline and fertility defects in C. elegans. Although set2(syb2085) and set-2(bn129) mutants became rapidly sterile at $25^{\circ} \mathrm{C}$, set-2(ok952) mutant animals remained fertile, consistent with only a modest loss of $\mathrm{H} 3 \mathrm{~K} 4 \mathrm{me} 2 / 3$ in these animals. Sterility in mutants lacking SET-2 catalytic activity may be related to altered chromatin organization or global deregulation of the germline transcriptional program, as we previously observed in the set-2(bn129) mutants (67, 68). Interestingly, a similar correlation was not observed between H3K4 methylation and the longevity phenotype, in that all three set-2 mutants showed a reduction in lifespan despite having markedly different global H3K4me2/3 levels. These results suggest that selective alteration in methylation patterns on specific genes, rather than a global decrease, may be responsible for the observed phenotype. In this regard, changes in H3K27me3 levels that affect the expression of relatively few genes have been shown to influence $C$. elegans lifespan (12, 13). Likewise, SET1/COMPASS-dependent H3K4me3 maintains normal chronological lifespan in yeast by specifically promoting histone gene expression (32). Our results could also be explained by the existence of a critical threshold of global H3K4me2/3 below which longevity is decreased. 
The results of our study provide novel insights into the controversy surrounding the impact of H3K4 methylation on longevity. In yeast, loss of SET1/COMPASS significantly shortens replicative lifespan, most likely via reduced expression of a set of genes that are normally induced during aging (33). In C. elegans, overexpression of the RBR-2 H3K4 demethylase extends lifespan (34), whereas mutations or RNAi-mediated knockdown of the same enzyme have been shown to either increase $(7,69,70)$ or decrease $(12,34)$ lifespan, depending on the allele used. Decreased longevity in rbr-2 mutants has been attributed to the presence of an additional mutation in the original genetic background (69). In Drosophila melanogaster, RNAi-mediated depletion or mutation of Lid, the RBR-2 ortholog, resulted in increased levels of H3K4me3 and reduced lifespan in males (71). Interestingly, depletion of LSD-1, another H3K4 demethylase targeting H3K4me1 and H3K4me2, has been shown to extend lifespan in C. elegans $(12,72)$. Taken together, these data and the results of the present study argue against a simple model in which $\mathrm{H} 3 \mathrm{~K} 4$ methylation and demethylation play opposing roles in lifespan regulation (34). Additional studies using well-characterized mutants and tissue-specific RNAi/deletion approaches will be required to clarify this complex relationship and to establish the contexts in which selective loss of SET1/COMPASSdependent H3K4 methylation alters the chromatin landscape during aging.

\section{Materials and Methods}

\section{Genetics and strains}

Strains were cultured under standard laboratory conditions (73). The WT N2 (Bristol) was used as reference strain. The strains used are as follows (name, genotype, and origin): PFR401, set-2(ok952) III, CGC; PFR253, set-2(bn129) III, (29); PFR588, cfp-1(tm6369) IV, NBRP; PHX2171, set-2(syb2085)/qC1[dpy-19(e1259) glp-1(q339) qls26] III, this work; PHX1012, cfp-1(syb1012) IV, this work; PFR727, cfp-1(syb1012) IV; set-2(ok952) III, this work; PFR728, cfp-1(syb1012) IV; set-2(syb2085) III, this work; PFR558, qals22[HA::wdr-5.1;Cbunc-119(+)]; set-2(bn129) III; wdr-5(ok1417) III (48); CB1370, daf-2(e1370) III, CGC; XA6226, mrg1(qa6200)/qC1 [dpy-19(e1259) glp-1(q339) qls26] III, CGC; and DA1116, eat-2(ad1116) II, CGC.

All mutants were outcrossed to WT N2 at least four times. cfp1(syb1012) and set-2(syb2085) were generated by CRISPR/Cas9 technology at SunyBiotech (Fuzhough City, Fujian, China). cfp1(syb1012) is a knock-in allele carrying a degron-GFP tag inserted at the $5^{\prime}$ end of the endogenous $c f p-1$ coding sequence. For set2(syb2085), the highly conserved histidine residue at amino acid position 1447 within the catalytic SET domain was replaced by lysine $(38,39)$. Two synonymous point mutations were introduced to avoid cutting of the repair template by Cas9. WT and syb2085 sequences are shown below, with the H1447K substitution in bold and synonymous mutations capitalized:

wt: aagcgtggaaattttgctcgatttatt AAT CAC tcgtgc CAA cctaattgctacgcgaaggta

syb2085: aagcgtggaaattttgctcgatttatt AAC AAG tcgtgc CAG cctaattgctacgcgaaggta
To avoid the potential accumulation of epigenetic modifications (37), set-2(syb2085) mutants were maintained in a heterozygous state by crossing them with XA6226 carrying the qC1 balancer chromosome (74).

\section{Lifespan analysis}

Lifespan assays were conducted at $20^{\circ} \mathrm{C}$ according to standard protocols (75). Worms were thawed and grown for three to four generations at $20^{\circ} \mathrm{C}$. Worms were synchronized by bleaching and transferred at the L1 stage. Worms were maintained on solid Nematode Growth Medium (NGM) seeded with Escherichia coli strain OP50-1. Solid NGM was prepared by mixing $3 \mathrm{~g}$ of $\mathrm{NaCl}$ (Euromedex), $2.5 \mathrm{~g}$ of peptone (BD), and $20 \mathrm{~g}$ of agar (Euromedex) in 1 liter of distilled water. After autoclaving $1 \mathrm{ml}$ of cholesterol (SigmaAldrich [5 mg/ml in ethanol]), $1 \mathrm{ml}$ of $1 \mathrm{M} \mathrm{MgSO}_{4}$ (Sigma-Aldrich), $1 \mathrm{ml}$ of $1 \mathrm{M} \mathrm{CaCl}_{2}$ (Euromedex), and $25 \mathrm{ml}$ of $1 \mathrm{M}(\mathrm{pH} 6.0) \mathrm{KPO}_{4}$ (Euromedex) were added. The medium was poured onto $35-\mathrm{mm}$ vented plates. 5-Fluoro-2'-deoxyuridine was not added to the plates. The L4 stage was considered day 0 . Hermaphrodites were transferred onto fresh seeded plates every day for the first week of the lifespan assay. Animals that failed to display heat-provoked movement were scored as dead, and animals that crawled off the plates or "bagged" worms were censored. P-values were calculated using the log-rank (Mantel-Cox) method. Statistical analysis of individual lifespan studies was performed using the Oasis online software (76). Statistical analysis of experiments shown in the main text and replicate experiments are provided in Table S3.

For experiments using the balanced strain PHX2171, non-roller set-2(syb2085) homozygotes were isolated and grown at $20^{\circ} \mathrm{C}$ for at least two generations before initiating the analysis to avoid the maternal effect.

\section{Brood size assay}

Ten L4 larvae were isolated on individual plates seeded with OP50-1 bacteria at $20^{\circ} \mathrm{C}$ and allowed to develop into egg-laying adults overnight. Adult animals were then transferred to fresh plates every $12 \mathrm{~h}$ until reproduction ceased. Plates were scored for the number of viable progeny $24 \mathrm{~h}$ after removal of the mother.

\section{Developmental time measurement}

Twenty gravid adults were allowed to lay eggs on NGM plates spotted with OP50-1 for $1 \mathrm{~h}$ and then removed. The time to egglaying adulthood was measured from this point. Eggs were allowed to hatch and 10 animals were randomly picked and transferred to individual plates. Plates bearing single young adults were checked every hour for the presence of eggs.

\section{Transgenerational fertility assays}

Six independent lines were established from freshly thawed WT animals, set-2(ok952) and set-2(bn129) mutants, and homozygous set-2(syb2085) mutants obtained from balanced strain PHX2171. For each line, six homozygous L4 stage animals were transferred to single plates seeded with OP50-1 and grown at $25^{\circ} \mathrm{C}$. From each 
generation, six worms were again picked and transferred to single plates until the animals became sterile (fewer than 10 larvae/ plate), as previously described (29). When at least 200 larvae were counted on a plate, the line was considered fully fertile.

\section{Oil Red 0 staining}

Worms were synchronized by bleaching and grown to the young adult stage at $20^{\circ} \mathrm{C}$ on NGM plates seeded with OP50-1. Worms were washed off the plates with $1 \times$ phosphate-buffered saline containing $0.1 \%$ Tween (PBST), placed in Eppendorf tubes, pelleted at $150 \mathrm{~g}$ for $30 \mathrm{~s}$, and washed three times with PBST. Worms were incubated with rocking for $3 \mathrm{~min}$ in $600 \mu \mathrm{l}$ of $40 \%$ isopropanol, the isopropanol was then removed, and the worms were mixed with $600 \mu \mathrm{l}$ of Oil Red 0 (3:2 ratio of $5 \mathrm{mg} / \mathrm{ml}$ Oil Red O/100\% isopropanol and sterile water). Animals were incubated on a rotator at RT for $2 \mathrm{~h}$, pelleted at $150 \mathrm{~g}$, and washed for $30 \mathrm{~min}$ in $600 \mu \mathrm{l}$ PBST. Aliquots of $10 \mu \mathrm{l}$ of stained animals were deposited onto freshly prepared 3\% agarose pads, covered with coverslips, and imaged with the same exposure settings at 10x magnification with a Zeiss Axiolmager Z1 equipped with a CoolSNAP color camera. Quantification of staining was performed using FIJI image processing software (35). Briefly, the original TIFF images were background subtracted, converted to grayscale, inverted, and thresholded. The intestinal cells of whole worms were selected using the oval brush tool, saved to the Region of Interest manager, and mean Oil Red O intensity was quantified. Experiments were performed twice with similar results.

\section{Western blot analysis}

Gravid animal were grown on NGM plates at $20^{\circ} \mathrm{C}$ and harvested for hypochlorite treatment. Mixed staged embryos ( $<100$ cells) obtained by this procedure were collected, pelleted in M9 buffer and flash frozen in liquid nitrogen. Pellets were recovered in TNET buffer (50 mM Tris- $\mathrm{HCl}$ pH 8.0, $300 \mathrm{mM} \mathrm{NaCl}, 1 \mathrm{mM}$ EDTA, and 0.5\% Triton $\mathrm{X}$-100 supplemented with cOmplete Easypack protease inhibitor cocktail [Sigma-Aldrich]). Samples were mixed 1:1 by volume with Lysing Matrix Y (MP Biomedicals) and lysed using a Precellys 24 homogenizer (Bertin) at two bursts of $20 \mathrm{~s} \mathrm{ON} \mathrm{at} \mathrm{6,000} \mathrm{rpm} \mathrm{with} 10 \mathrm{~s}$ OFF between bursts. Samples were then centrifuged at $4^{\circ} \mathrm{C}$ for $5 \mathrm{~min}$ at 20,000 $\mathrm{g}$ and protein concentrations in supernatants were measured using the Bradford assay (Bio-Rad Protein Assay Dye). Aliquots equivalent to 1 and $3 \mu \mathrm{g}$ protein were separated on NUAGE $12 \%$ Bis-Tris Gels using MOPS 1 X (Invitrogen) running buffer, and then transferred to $0.45 \mu \mathrm{M}$ nitrocellulose membranes (Bio-Rad Laboratories). Membranes were blocked with PBST containing 5\% non-fat dry milk, and incubated overnight at $4^{\circ} \mathrm{C}$ with anti-H3 (\#14269 at 1:2,500 dilution in PBST containing 1\% BSA; Cell Signaling Technology), anti-H3K4me2 (\#39913 at 1:2,000; Active Motif), or anti-H3K4me3 (\#A2357 at 1:2,000; AB Clonal) primary antibodies. The membranes were washed then four times in PBST, incubated with secondary antibodies: IRDye 800CW goat anti-Rabbit (\# 926-32211 at 1:10,000; LI-COR Biosciences) and IRDye 680 RD goat anti-Mouse (\# 925-68070 at 1:10,000; LI-COR Biosciences). Images were obtained with the Chemidoc MP Imaging System (Bio-Rad Laboratories) and fluorescent signals were quantified using Image Lab software (BioRad Laboratories).

\section{Immunofluorescence microscopy}

Gonads were fixed essentially as previously described (77) and incubated overnight at $4^{\circ} \mathrm{C}$ with mouse anti-H4K3me3 (\#305-34819 at 1:500 dilution in PBST; Wako) or rabbit anti-H3K4me2 (\#710796 at 1: 20,000; Invitrogen) primary antibodies. Slides were washed with PBST, and incubated at RT for 50 min with goat anti-mouse Alexa Fluor Plus 555 (\#A32727 at 1:1,000; Invitrogen/Probes) or goat antirabbit Alexa Fluor Plus 647 (\#A32733 at 1:1,000; Invitrogen/Molecular Probes) secondary antibodies. Slides were washed again in PBST and DNA was stained with Hoechst. Alternatively, a double immunofluorescence assay was performed by incubating simultaneously with a mix of anti-H3K4me2 and rabbit anti-H3 (\#39163 at 1: 500; Active Motif) primary antibodies. Washing steps and incubation with goat anti-rabbit Alexa Fluor Plus 647 were as explained above. Images were acquired with a YOKOGAWA CQ1 spinning disk confocal microscope. Maximum intensity projections of whole germlines acquired with the same settings were opened in ImageJ, and 10 germlines per strain over two biological replicates were processed identically. Intensities of antibody signal from the distal germline (mitotic and transition zones) or the mid-germline (early and midpachytene regions) were measured, normalized to either Hoechst or H3 signal, and averaged. Because comparable results were obtained regardless of the normalization used (Fig S2A and B), we routinely used Hoechst-based normalization.

\section{Immunoprecipitation for proteomics}

Immunoprecipitations were performed on frozen embryos prepared by hypochlorite treatment from animals grown at $20^{\circ} \mathrm{C}$ on enriched NGM seeded with concentrated HB101 bacteria. After hypochlorite treatment, embryos were washed once in IP buffer $(50 \mathrm{mM}$ HEPES/ KOH, pH 7.5; 300 mM KCl; 1 mM EDTA; 1 mM MgCl $2 ; 0.2 \%$ IgepalCA630; and 10\% glycerol) and flash-frozen in liquid nitrogen after the addition of beads. Embryos were then grounded to powder, resuspended in IP buffer containing complete protease inhibitors (Roche) and sonicated on ice at an amplitude of $30 \%$ for $2.5 \mathrm{~min}$ (15" ON/15" OFF pulses) using an Ultrasonic Processor (Bioblock Scientific). Protein extracts were recovered in the supernatant after centrifugation at 20,000 $\mathrm{g}$ for $15 \mathrm{~min}$ at $4^{\circ} \mathrm{C}$. Protein concentration was estimated using the Bradford assay (Bio-Rad Protein Assay Dye).

For all GFP immunoprecipitations, $70 \mathrm{mg}$ of total protein extract was incubated for preclearing with $200 \mu \mathrm{l}$ slurry of binding control magnetic agarose beads (ChromoTek bmab-20) in IP buffer for $1 \mathrm{~h}$ at $4^{\circ} \mathrm{C}$. Then $200 \mu \mathrm{l}$ of GFP-TRAP MA beads slurry (ChromoTek) were added to each sample and incubation continued for additional $3 \mathrm{~h}$ on a rotator. Beads were collected with a magnet, washed three times in IP buffer and once in Benzo buffer (HEPES/ KOH $50 \mathrm{mM}, \mathrm{pH}$ 7.5; KCl 150 mM; EDTA 1 mM; MgCl 1 mM; Igepal-CA630 0.2\%; and glycerol 10\%). Beads were then incubated in $400 \mu$ l of Benzo buffer containing 2,500 units of benzonase (Sigma-Aldrich) for $1 \mathrm{~h}$ at $4^{\circ} \mathrm{C}$ and washed three times in IP buffer. Eluates were recovered by incubation at $95^{\circ} \mathrm{C}$ for $10 \mathrm{~min}$ in $60 \mu \mathrm{l}$ of $1 \times$ LDS buffer (Thermo Fisher Scientific). $1 / 10$ of each eluate was resolved on a $4-12 \%$ NuPage 
Novex gel (Thermo Fisher Scientific) and stained with SilverQuest staining kit (Thermo Fisher Scientific). $40 \mu$ of the eluates was then analyzed by mass spectrometry.

For HA::WDR-5.1 co-immunoprecipitation, samples were prepared as described previously (48).

\section{Mass spectrometry-based proteomic analyses}

For the GFP co-immunoprecipitation: The eluted proteins were stacked at the top of a 4-12\% NuPAGE gel (Invitrogen). After staining with R-250 Coomassie Blue (Bio-Rad Laboratories), proteins were digested in-gel using modified trypsin (sequencing purity; Promega), as previously described (78). The resulting peptides were analyzed by online nanoliquid chromatography coupled to MS/MS (Ultimate 3000 RSLCnano and Q-Exactive HF; Thermo Fisher Scientific) using a 120 min gradient. To this end, peptides were sampled on a precolumn $(300 \mu \mathrm{m} \times 5 \mathrm{~mm}$ PepMap C18; Thermo Fisher Scientific) and separated in a $75 \mu \mathrm{m} \times 250 \mathrm{~mm}$ C18 column (Reprosil-Pur 120 C18-AQ, $1.9 \mu \mathrm{m}$; Dr. Maisch). The MS and MS/MS data were acquired by Xcalibur (Thermo Fisher Scientific).

Peptides and proteins were identified by Mascot (version 2.7.0; Matrix Science) through concomitant searches against the Uniprot database (C. elegans taxonomy, January 2021 version), classical contaminants database (homemade), and the corresponding reversed databases. Trypsin/P was used for digestion and two missed cleavages were allowed. Precursor and fragment mass error tolerances were set at 10 and 20 ppm, respectively. Peptide modifications allowed during the search were carbamidomethyl (C, fixed), acetyl (Protein N-term, variable), and oxidation ( $M$, variable). The Proline software (79) was used for the compilation, grouping and filtering of the results (conservation of rank 1 peptides, peptide length $\geq 6$ amino acids, peptide score $\geq 25$, and false discovery rate of peptide-spectrum-match identifications $<1 \%$ as calculated on peptide-spectrum-match scores by employing the reverse database strategy). Proline was then used to perform a compilation, grouping, and spectral counting-based comparison of the protein groups identified in the different samples. Proteins from the contaminant database were discarded from the final list of identified proteins. To be considered as a potential CFP-1 interactor, a protein must be identified with a minimum of three specific spectral counts and not in the negative control eluate, or enriched at least five times relative to the negative control eluate.

For the HA::WDR-5.1 mass spectrometry, samples were prepared and analyzed as described previously (48).

\section{Data Availability}

The mass spectrometry proteomics data have been deposited to the ProteomeXchange Consortium via the PRIDE (PubMed ID: 30395289) partner repository with the dataset identifier PXD029904.

\section{Supplementary Information}

Supplementary Information is available at https://doi.org/10.26508/lsa. 202101140.

\section{Acknowledgements}

Strains were obtained from the Caenorhabditis Genetics Center (CGC), supported by the National Institutes of Health Office of Infrastructure Programs (P40 OD010440), and the National BioResource Project. We acknowledge the Discovery Platform and Informatics Group at EDyP (U1292 INSERM/CEA/UGA, Institut de Recherche Interdisciplinaire de Grenoble, IRIG), and the SFR Biosciences (UAR3444/CNRS, US8/Inserm, ENS de Lyon, UCBL): PLATIM. We thank Cécile Bedet, Laura Faccin, and Lisa-May Alvarez for technical support. We also thank Anne O'Rourke for critical reading of the manuscript and Florence Solari and Valérie Robert for helpful discussions. This project was supported by the Agence Nationale de la Recherche (ANR) [15-CE12-0018-01] and [ANR-19-CE12-0025] and the Centre National de la Recherche Scientifique (CNRS). The proteomic experiments were partially supported by ANR under projects ProFI (Proteomics French Infrastructure, ANR-10-INBS-08) and GRAL, a program from the Chemistry Biology Health (CBH) Graduate School of the University of Grenoble Alpes (ANR-17-EURE-0003).

\section{Author Contributions}

M Caron: conceptualization, formal analysis, supervision, investigation, visualization, and writing-review and editing.

L Gely: formal analysis, investigation, and visualization.

S Garvis: formal analysis, investigation, and writing-editing.

A Adrait: formal analysis, data curation, and investigation.

Y Couté: formal analysis, data curation, and investigation.

F Palladino: conceptualization, funding acquisition, project administration, and writing-original draft, review, and editing.

P Fabrizio: conceptualization, project administration, validation, formal analysis, supervision, investigation, visualization, and writing-original draft, review, and editing.

\section{Conflict of Interest Statement}

The authors declare that they have no conflict of interest.

\section{References}

1. Pal S, Tyler JK (2016) Epigenetics and aging. Sci Adv 2: e1600584. doi:10.1126/sciadv.1600584

2. Sen P, Shah PP, Nativio R, Berger SL (2016) Epigenetic mechanisms of longevity and aging. Cell 166: 822-839. doi:10.1016/j.cell.2016.07.050

3. Fontana L, Partridge L, Longo VD (2010) Extending healthy life span-from yeast to humans. Science 328: 321-326. doi:10.1126/science.1172539

4. Longo VD, Fabrizio P (2002) Regulation of longevity and stress resistance: A molecular strategy conserved from yeast to humans? Cell Mol Life Sci 59: 903-908. doi:10.1007/s00018-002-8477-8

5. Dang W, Steffen KK, Perry R, Dorsey JA, Johnson FB, Shilatifard A, Kaeberlein M, Kennedy BK, Berger SL (2009) Histone H4 lysine 16 acetylation regulates cellular lifespan. Nature 459: 802-807. doi:10.1038/ nature08085

6. Feser J, Truong D, Das C, Carson JJ, Kieft J, Harkness T, Tyler JK (2010) Elevated histone expression promotes life span extension. Mol Cell 39 : 724-735. doi:10.1016/j.molcel.2010.08.015

7. Ni Z, Ebata A, Alipanahiramandi E, Lee SS (2012) Two SET domain containing genes link epigenetic changes and aging in Caenorhabditis elegans. Aging Cell 11: 315-325. doi:10.1111/j.1474-9726.2011.00785.x

8. Ivanov A, Pawlikowski J, Manoharan I, van Tuyn J, Nelson DM, Rai TS, Shah PP, Hewitt G, Korolchuk VI, Passos JF, et al (2013) Lysosome-mediated 
processing of chromatin in senescence. J Cell Biol 202: 129-143. doi:10.1083/jcb.201212110

9. O'Sullivan RJ, Kubicek S, Schreiber SL, Karlseder J (2010) Reduced histone biosynthesis and chromatin changes arising from a damage signal at telomeres. Nat Struct Mol Biol 17: 1218-1225. doi:10.1038/nsmb.1897

10. Lee JH, Kim EW, Croteau DL, Bohr VA (2020) Heterochromatin: An epigenetic point of view in aging. Exp Mol Med 52: 1466-1474. doi:10.1038/ s12276-020-00497-4

11. Kane AE, Sinclair DA (2019) Epigenetic changes during aging and their reprogramming potential. Crit Rev Biochem Mol Biol 54: 61-83. doi:10.1080/10409238.2019.1570075

12. Maures TJ, Greer EL, Hauswirth AG, Brunet A (2011) The H3K27 demethylase UTX-1 regulates C. elegans lifespan in a germlineindependent, insulin-dependent manner. Aging Cell 10: 980-990. doi:10.1111/j.1474-9726.2011.00738.x

13. Jin C, Li J, Green CD, Yu X, Tang X, Han D, Xian B, Wang D, Huang X, Cao X, et al (2011) Histone demethylase UTX-1 regulates $C$. elegans life span by targeting the insulin/IGF-1 signaling pathway. Cell Metab 14: 161-172. doi:10.1016/j.cmet.2011.07.001

14. Siebold AP, Banerjee R, Tie F, Kiss DL, Moskowitz J, Harte PJ (2010) Polycomb Repressive Complex 2 and Trithorax modulate Drosophila longevity and stress resistance. Proc Natl Acad Sci U S A 107: 169-174. doi:10.1073/pnas.0907739107

15. Guillermo ARR, Chocian K, Gavriilidis G, Vandamme J, Salcini AE, Mellor J, Woollard A (2021) H3K27 modifiers regulate lifespan in C. elegans in a context-dependent manner. BMC Biol 19: 59. doi:10.1186/s12915-02100984-8

16. Benayoun BA, Pollina EA, Brunet A (2015) Epigenetic regulation of ageing: Linking environmental inputs to genomic stability. Nat Rev Mol Cell Biol 16: 593-610. doi:10.1038/nrm4048

17. Shilatifard A (2012) The COMPASS family of histone H3K4 methylases: Mechanisms of regulation in development and disease pathogenesis. Annu Rev Biochem 81: 65-95. doi:10.1146/annurev-biochem-051710134100

18. Miller T, Krogan NJ, Dover J, Erdjument-Bromage $H$, Tempst $P$, Johnston $M$, Greenblatt JF, Shilatifard A (2001) COMPASS: A complex of proteins associated with a trithorax-related SET domain protein. Proc Natl Acad Sci U S A 98: 12902-12907. doi:10.1073/pnas.231473398

19. Roguev A, Schaft D, Shevchenko A, Pijnappel WW, Wilm M, Aasland R, Stewart AF (2001) The Saccharomyces cerevisiae Set1 complex includes an Ash2 homologue and methylates histone 3 lysine 4. EMBO I 20: 7137-7148. doi:10.1093/emboj/20.24.7137

20. Dehé PM, Dichtl B, Schaft D, Roguev A, Pamblanco M, Lebrun $R$ Rodriguez-Gil A, Mkandawire M, Landsberg K, Shevchenko A, et al (2006) Protein interactions within the Set1 complex and their roles in the regulation of histone 3 lysine 4 methylation. J Biol Chem 281: 35404-35412. doi:10.1074/jbc.M603099200

21. Dou Y, Milne TA, Ruthenburg AJ, Lee S, Lee JW, Verdine GL, Allis CD, Roeder RG (2006) Regulation of MLL1 H3K4 methyltransferase activity by its core components. Nat Struct Mol Biol 13: 713-719. doi:10.1038/nsmb1128

22. Steward MM, Lee JS, O'Donovan A, Wyatt M, Bernstein BE, Shilatifard A (2006) Molecular regulation of H3K4 trimethylation by $\mathrm{ASH} 2 \mathrm{~L}$, a shared subunit of MLL complexes. Nat Struct Mol Biol 13: 852-854. doi:10.1038/ nsmb1131

23. Lee JH, Skalnik DG (2005) CpG-binding protein (CXXC finger protein 1) is a component of the mammalian Set1 histone H3-Lys4 methyltransferase complex, the analogue of the yeast Set1/COMPASS complex. J Biol Chem 280: 41725-41731. doi:10.1074/jbc.M508312200

24. Lee S, Lee DK, Dou Y, Lee J, Lee B, Kwak E, Kong YY, Lee SK, Roeder RG, Lee JW (2006) Coactivator as a target gene specificity determinant for histone H3 lysine 4 methyltransferases. Proc Natl Acad Sci U S A 103 : 15392-15397. doi:10.1073/pnas.0607313103
25. Narayanan A, Ruyechan WT, Kristie TM (2007) The coactivator host cell factor-1 mediates Set1 and MLL1 H3K4 trimethylation at herpesvirus immediate early promoters for initiation of infection. Proc Natl Acad SC U S A 104: 10835-10840. doi:10.1073/pnas.0704351104

26. Tyagi S, Chabes AL, Wysocka J, Herr W (2007) E2F activation of S phase promoters via association with HCF-1 and the MLL family of histone H3K4 methyltransferases. Mol Cell 27: 107-119. doi:10.1016/j.molcel.2007.05.030

27. Simonet T, Dulermo R, Schott S, Palladino F (2007) Antagonistic functions of SET-2/SET1 and HPL/HP1 proteins in C. elegans development. Dev Biol 312: 367-383. doi:10.1016/j.ydbio.2007.09.035

28. Fisher K, Southall SM, Wilson JR, Poulin GB (2010) Methylation and demethylation activities of a C. elegans MLL-like complex attenuate RAS signalling. Dev Biol 341: 142-153. doi:10.1016/j.ydbio.2010.02.023

29. Xiao Y, Bedet C, Robert VJ, Simonet T, Dunkelbarger S, Rakotomalala C Soete G, Korswagen HC, Strome S, Palladino F (2011) Caenorhabditis elegans chromatin-associated proteins SET-2 and ASH-2 are differentially required for histone $\mathrm{H} 3$ Lys 4 methylation in embryos and adult germ cells. Proc Natl Acad Sci U S A 108: 8305-8310. doi:10.1073/ pnas.1019290108

30. Andersen EC, Horvitz HR (2007) Two C. elegans histone methyltransferases repress lin-3 EGF transcription to inhibit vulval development. Development 134: 2991-2999. doi:10.1242/dev.009373

31. Walter D, Matter A, Fahrenkrog B (2014) Loss of histone $\mathrm{H} 3$ methylation at lysine 4 triggers apoptosis in Saccharomyces cerevisiae. PLoS Genet 10 : e1004095. doi:10.1371/journal.pgen.1004095

32. Mei Q, Xu C, Gogol M, Tang J, Chen W, Yu X, Workman JL, Li S (2019) Set1 catalyzed H3K4 trimethylation antagonizes the HIR/Asf1/Rtt106 repressor complex to promote histone gene expression and chronological life span. Nucleic Acids Res 47: 3434-3449. doi:10.1093/ nar/gkz101

33. Cruz C, Rosa MD, Krueger C, Gao Q, Horkai D, King M, Field L, Houseley J (2018) Tri-methylation of histone $\mathrm{H} 3$ lysine 4 facilitates gene expression in ageing cells. Elife 7: e34081. doi:10.7554/eLife.34081

34. Greer EL, Maures TJ, Hauswirth AG, Green EM, Leeman DS, Maro GS, Han S, Banko MR, Gozani O, Brunet A (2010) Members of the H3K4 trimethylation complex regulate lifespan in a germline-dependent manner in C. elegans. Nature 466: 383-387. doi:10.1038/nature09195

35. Han S, Schroeder EA, Silva-García CG, Hebestreit K, Mair WB, Brunet A (2017) Mono-unsaturated fatty acids link H3K4me3 modifiers to C. elegans lifespan. Nature 544: 185-190. doi:10.1038/nature21686

36. Greer EL, Maures TJ, Ucar D, Hauswirth AG, Mancini E, Lim JP, Benayoun BA, Shi Y, Brunet A (2011) Transgenerational epigenetic inheritance of longevity in Caenorhabditis elegans. Nature 479: 365-371. doi:10.1038/ nature10572

37. Lee TW, David HS, Engstrom AK, Carpenter BS, Katz DJ (2019) Repressive $\mathrm{H} 3 \mathrm{~K} 9 \mathrm{me} 2$ protects lifespan against the transgenerational burden of COMPASS activity in C. elegans. Elife 8: e48498. doi:10.7554/eLife.48498

38. Rizzardi LF, Dorn ES, Strahl BD, Cook JG (2012) DNA replication origin function is promoted by $\mathrm{H} 3 \mathrm{~K} 4$ di-methylation in Saccharomyces cerevisiae. Genetics 192: 371-384. doi:10.1534/genetics.112.142349

39. Schlichter A, Cairns BR (2005) Histone trimethylation by Set1 is coordinated by the RRM, autoinhibitory, and catalytic domains. EMBO 24: 1222-1231. doi:10.1038/sj.emboj.7600607

40. South PF, Harmeyer KM, Serratore ND, Briggs SD (2013) H3K4 methyltransferase Set1 is involved in maintenance of ergosterol homeostasis and resistance to Brefeldin A. Proc Natl Acad Sci U S A 110: E1016-E1025. doi:10.1073/pnas.1215768110

41. Soares LM, Radman-Livaja M, Lin SG, Rando OJ, Buratowski S (2014) Feedback control of Set1 protein levels is important for proper H3K4 methylation patterns. Cell Rep 6: 961-972. doi:10.1016/j.celrep.2014.02.017

42. Williamson K, Schneider V, Jordan RA, Mueller JE, Pozzi MH, Bryk M (2013) Catalytic and functional roles of conserved amino acids in the SET 
domain of the S. cerevisiae lysine methyltransferase Set1. PLoS One 8: e57974. doi:10.1371/journal.pone.0057974

43. Wilson JR, Jing C, Walker PA, Martin SR, Howell SA, Blackburn GM, Gamblin SJ, Xiao B (2002) Crystal structure and functional analysis of the histone methyltransferase SET7/9. Cell 111: 105-115. doi:10.1016/s0092-8674(02) 00964-9

44. Kwon T, Chang JH, Kwak E, Lee CW, Joachimiak A, Kim YC, Lee J, Cho Y (2003) Mechanism of histone lysine methyl transfer revealed by the structure of SET7/9-AdoMet. EMBO / 22: 292-303. doi:10.1093/emboj/ cdg025

45. Qian C, Zhou MM (2006) SET domain protein lysine methyltransferases: Structure, specificity and catalysis. Cell Mol Life Sci 63: 2755-2763. doi:10.1007/s00018-006-6274-5

46. Cao F, Chen Y, Cierpicki T, Liu Y, Basrur V, Lei M, Dou Y (2010) An Ash2L/ RbBP5 heterodimer stimulates the MLL1 methyltransferase activity through coordinated substrate interactions with the MLL1 SET domain. PLoS One 5: e14102. doi:10.1371/journal.pone.0014102

47. Trievel RC, Beach BM, Dirk LM, Houtz RL, Hurley JH (2002) Structure and catalytic mechanism of a SET domain protein methyltransferase. Cell 111: 91-103. doi:10.1016/s0092-8674(02)01000-0

48. Beurton F, Stempor P, Caron M, Appert A, Dong Y, Chen RA, Cluet D, Couté $\mathrm{Y}$, Herbette M, Huang N, et al (2019) Physical and functional interaction between SET1/COMPASS complex component CFP-1 and a Sin3S HDAC complex in C. elegans. Nucleic Acids Res 47: 11164-11180. doi:10.1093/ nar/gkz880

49. Li T, Kelly WG (2011) A role for Set1/MLL-related components in epigenetic regulation of the Caenorhabditis elegans germ line. PLOS Genet 7: e1001349. doi:10.1371/journal.pgen.1001349

50. Wang S, Meyer DH, Schumacher B (2020) H3K4me2 regulates the recovery of protein biosynthesis and homeostasis following DNA damage. Nat Struct Mol Biol 27: 1165-1177. doi:10.1038/s41594-02000513-1

51. Ashrafi K, Chang FY, Watts JL, Fraser AG, Kamath RS, Ahringer J, Ruvkun G (2003) Genome-wide RNAi analysis of Caenorhabditis elegans fat regulatory genes. Nature 421: 268-272. doi:10.1038/nature01279

52. Kenyon C, Chang J, Gensch E, Rudner A, Tabtiang R (1993) A C. elegans mutant that lives twice as long as wild type. Nature 366: 461-464. doi:10.1038/366461a0

53. Lakowski B, Hekimi S (1998) The genetics of caloric restriction in Caenorhabditis elegans. Proc Natl Acad Sci U S A 95: 13091-13096. doi:10.1073/pnas.95.22.13091

54. Nhan JD, Turner CD, Anderson SM, Yen CA, Dalton HM, Cheesman HK, Ruter DL, Naresh NU, Haynes CM, Soukas AA, et al (2019) Redirection of SKN-1 abates the negative metabolic outcomes of a perceived pathogen infection. Proc Natl Acad Sci U S A 116: 22322-22330. doi:10.1073/ pnas.1909666116

55. Briese M, Esmaeili B, Fraboulet S, Burt EC, Christodoulou S, Towers PR, Davies KE, Sattelle DB (2009) Deletion of smn-1, the Caenorhabditis elegans ortholog of the spinal muscular atrophy gene, results in locomotor dysfunction and reduced lifespan. Hum Mol Genet 18: 97-104. doi:10.1093/hmg/ddn320

56. Abay-N $\varnothing$ rgaard S, Attianese B, Boreggio L, Salcini AE (2020) Regulators of $\mathrm{H} 3 \mathrm{~K} 4$ methylation mutated in neurodevelopmental disorders control axon guidance in Caenorhabditis elegans. Development 147: dev190637. doi:10.1242/dev.190637

57. Robert VJ, Mercier MG, Bedet C, Janczarski S, Merlet J, Garvis S, Ciosk R, Palladino F (2014) The SET-2/SET1 histone H3K4 methyltransferase maintains pluripotency in the Caenorhabditis elegans germline. Cell Rep 9: 443-450. doi:10.1016/j.celrep.2014.09.018

58. Morgan MAJ, Shilatifard A (2020) Reevaluating the roles of histonemodifying enzymes and their associated chromatin modifications in transcriptional regulation. Nat Genet 52: 1271-1281. doi:10.1038/s41588020-00736-4
59. Lithgow GJ, Driscoll M, Phillips P (2017) A long journey to reproducible results. Nature 548: 387-388. doi:10.1038/548387a

60. Lucanic M, Plummer WT, Chen E, Harke J, Foulger AC, Onken B, ColemanHulbert AL, Dumas KJ, Guo S, Johnson E, et al (2017) Impact of genetic background and experimental reproducibility on identifying chemical compounds with robust longevity effects. Nat Commun 8: 14256. doi:10.1038/ncomms14256

61. Burnett C, Valentini S, Cabreiro F, Goss M, Somogyvári M, Piper MD, Hoddinott M, Sutphin GL, Leko V, McElwee JJ, et al (2011) Absence of effects of Sir2 overexpression on lifespan in C. elegans and Drosophila. Nature 477: 482-485. doi:10.1038/nature10296

62. Dias J, Van Nguyen N, Georgiev P, Gaub A, Brettschneider J, Cusack S, Kadlec J, Akhtar A (2014) Structural analysis of the KANSL1/WDR5/ KANSL2 complex reveals that WDR5 is required for efficient assembly and chromatin targeting of the NSL complex. Genes Dev 28: 929-942. doi:10.1101/gad.240200.114

63. Milne TA, Dou Y, Martin ME, Brock HW, Roeder RG, Hess JL (2005) MLL associates specifically with a subset of transcriptionally active target genes. Proc Natl Acad Sci U S A 102: 14765-14770. doi:10.1073/ pnas. 0503630102

64. Raja SJ, Charapitsa I, Conrad T, Vaquerizas JM, Gebhardt P, Holz H, Kadlec J, Fraterman S, Luscombe NM, Akhtar A (2010) The nonspecific lethal complex is a transcriptional regulator in Drosophila. Mol Cell 38: 827-841. doi:10.1016/j.molcel.2010.05.021

65. Zhao X, Su J, Wang F, Liu D, Ding J, Yang Y, Conaway JW, Conaway RC, Cao L, Wu D, et al (2013) Crosstalk between NSL histone acetyltransferase and MLL/SET complexes: NSL complex functions in promoting histone H3K4 di-methylation activity by MLL/SET complexes. PLOS Genet 9: e1003940. doi:10.1371/journal.pgen.1003940

66. Li T, Kelly WG (2014) A role for WDR5 in TRA-1/Gli mediated transcriptional control of the sperm/ oocyte switch in C. elegans. Nucleic Acids Res 42: 5567-5581. doi:10.1093/nar/gku221

67. Herbette M, Robert V, Bailly A, Gely L, Feil R, Llères D, Palladino F (2020) A role for Caenorhabditis elegans COMPASS in germline chromatin organization. Cells 9: 2049. doi:10.3390/cells9092049

68. Robert VI, Knutson AK, Rechtsteiner A, Garvis S, Yvert G, Strome S, Palladino F (2020) Caenorhabditis elegans SET1/COMPASS maintains germline identity by preventing transcriptional deregulation across generations. Front Cell Dev Biol 8: 561791. doi:10.3389/fcell.2020.561791

69. Alvares SM, Mayberry GA, Joyner EY, Lakowski B, Ahmed S (2014) H3K4 demethylase activities repress proliferative and postmitotic aging. Aging Cell 13: 245-253. doi:10.1111/acel.12166

70. Lee SS, Lee RY, Fraser AG, Kamath RS, Ahringer J, Ruvkun G (2003) A systematic RNAi screen identifies a critical role for mitochondria in C. elegans longevity. Nat Genet 33: 40-48. doi:10.1038/ng1056

71. Li L, Greer C, Eisenman RN, Secombe J (2010) Essential functions of the histone demethylase lid. PLoS Genet 6: e1001221. doi:10.1371/journal.pgen.1001221

72. McColl G, Killilea DW, Hubbard AE, Vantipalli MC, Melov S, Lithgow GJ (2008) Pharmacogenetic analysis of lithium-induced delayed aging in Caenorhabditis elegans. J Biol Chem 283: 350-357. doi:10.1074/jbc.M705028200

73. Brenner S (1974) The genetics of Caenorhabditis elegans. Genetics 77: 71-94. doi:10.1093/genetics/77.1.71

74. Edgley ML, Riddle DL (2001) LG II balancer chromosomes in Caenorhabditis elegans: $\mathrm{mT} 1(I|;| I I)$ and the $\mathrm{mIn} 1$ set of dominantly and recessively marked inversions. Mol Genet Genomics 266: 385-395. doi:10.1007/s004380100523

75. Sutphin GL, Kaeberlein M (2009) Measuring Caenorhabditis elegans life span on solid media. J Vis Exp 27: 1152. doi:10.3791/1152

76. Yang JS, Nam HJ, Seo M, Han SK, Choi Y, Nam HG, Lee SJ, Kim S (2011) OASIS: Online application for the survival analysis of lifespan assays performed in aging research. PLoS One 6: e23525. doi:10.1371/ journal.pone.0023525 


\section{Life Science Alliance}

77. Herbette M, Mercier MG, Michal F, Cluet D, Burny C, Yvert G, Robert VJ, Palladino F (2017) The C. elegans SET-2/SET1 histone H3 Lys4 (H3K4) methyltransferase preserves genome stability in the germline. DNA Repair (Amst) 57: 139-150. doi:10.1016/j.dnarep.2017.07.007

78. Casabona MG, Vandenbrouck Y, Attree I, Couté Y (2013) Proteomic characterization of Pseudomonas aeruginosa PAO1 inner membrane. Proteomics 13: 2419-2423. doi:10.1002/pmic.201200565

79. Bouyssié D, Hesse AM, Mouton-Barbosa E, Rompais M, Macron C, Carapito C, Gonzalez de Peredo A, Couté Y, Dupierris V, Burel A, et al
(2020) Proline: An efficient and user-friendly software suite for largescale proteomics. Bioinformatics 36: 3148-3155. doi:10.1093/ bioinformatics/btaa118

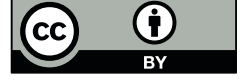

License: This article is available under a Creative Commons License (Attribution 4.0 International, as described at https://creativecommons.org/ licenses/by/4.0/). 